\title{
Effervescent tablet-assisted switchable hydrophilicity solvent- based on-site dispersive liquid-liquid microextraction coupled with gas chromatography for the determination of pyrethroid pesticides in environmental waters
}

\author{
Wentao Han, Kejiao Hu, Wanning Zhao, Songqing $\mathrm{Li}^{*}$, and Pengfei $\mathrm{Lu}$ \\ Key Laboratory of Beijing for the Control of Forest Pests, Beijing Forestry University, Beijing, China
}

\begin{abstract}
A novel effervescent tablet-assisted switchable hydrophilicity solvent-based on-site dispersive liquid-liquid microextraction coupled with gas chromatography detection has been developed to determine five pyrethroid insecticides in environmental water samples. In this method, effervescent tablets contain effervescent precursors and extractants, which play a dual role of dispersion and extraction. After effervescence reaction, the formation of extractant and the extraction of analytes were accomplished simultaneously. Phase separation were carried by filtration using homemade filter column, which of filter is oil-absorbing cotton polypropylene. After phase separation, the extractant phase were obtained by elution. No electric instrument was required in sample pre-treatment step in the developed method. Experimental conditions affecting the extraction efficiencies have been optimized, such as type and amount of extractant, type of effervescent tablets, etc. Under the optimized conditions, the linearity was 5$500 \mu \mathrm{g} \mathrm{L}^{-1}$, with coefficients greater than 0.9990 . The limit of detection and the limit of quantitation were in the range of $0.22-1.88 \mu \mathrm{g} \mathrm{L}^{-1}$ and $0.75-6.25 \mu \mathrm{g} \mathrm{L} \mathrm{L}^{-1}$. The relative standard deviations ranged from $0.8 \%$ to $6.1 \%$. The enrichment factors were in the range of $65-108$. This method was successfully applied to the on-site processing of tap, reservoir and river water.
\end{abstract}

\section{Introduction}

Forests, as an important resource of a country, play an important role in preventing soil erosion and improving the ecological environment which bring good ecological and social benefits [1]. However, forests have been constantly infested with pests and plant diseases, and a large number of pesticides have been used to control the occurrence of pests and plant diseases. During the chemical protection, a large number of pesticides are sprayed on the forest land, and some pesticide residues will be infiltrated into the ground and flowed into the lake through the river, which will inevitably cause certain pollution to the environment [2].

Pyrethroid insecticides are widely used insecticides, a synthetic derivative of pyrethroid derived from chrysanthemum and plant flowers [3]. They are often used to control or eliminate areas such as forestry and agriculture [4]. According to reports, more than 3,700 tons of pyrethroid pesticides are consumed annually in China for pest control in agriculture, forestry, horticulture and industry [5]. Howerer, long-term excessive exposure to pyrethroids can cause serious health problems, including vomiting, nausea, respiratory depression, etc. [6]. Thus, it is important to determine pyrethroid insecticides in environmental waters.

Due to the complexity and low concentration of the sample, the step of sample preconcentration is inevitable before detection. Traditional extraction methods include liquid-liquid extraction (LLE) [7], soxhlet extraction [8], and solid phase extraction (SPE) [9]. The LLE is easy to use and does not require complex instrument execution. However, high consumption of highly toxic organic solvents and low selectivity for extracting analyses limits the use of the LLE method. SPE consumes a relatively small amount of organic solvent relative to LLE, but it is relatively expensive and time consuming [10]. Therefore, in recent years, sample pretreatment technology has been developing in the direction of miniaturization and simplification.

Dispersive liquid-liquid microextraction (DLLME) is commonly used method for the determination of pesticide residues, with the advantages of simple, fast and efficient. It was proposed by Rezaee et al. in 2006 [11]. The technology mainly includes two steps: solvent dispersion and recovery. Traditional DLLME uses a dispersant for dispersion, which consumes both organic solvents and reduces the partition coefficient of the analyte. In recent years, an auxiliary dispersion method that does not require a dispersant has been developed, which enriches the DLLME technique. Specific dispersion techniques include manual shaking [12], vortex [13], ultrasound [14], microwave [15], and so on. Manual shaking is gradually replaced by other methods

\footnotetext{
*Corresponding author: songqingli@bjfu.edu.cn
} 
because of poor reproducibility, and several other methods require the use of instruments for operation, which is difficult to perform on site. In 2014, LasadeAragones et al. first introduced effervescence-assisted DLLME which the extraction solvent was dispersed by an effervescence reaction between an acid and a carbonate or bicarbonate [16]. Because it is not limited by instruments such as ultrasound and vortex, it has the possibility of on-site processing and are increasingly popular for the advantages of small side effects [17].

Recently, switchable hydrophilicity solvents (SHS) have been used as an extractant in liquid-liquid microextraction [18]. Medium-chain fatty acids are considered as an SHS [19]. The mechanism is that the conversion between soluble and insoluble can be achieved by adjusting the $\mathrm{pH}$ [20]. Moreover, the medium-chain fatty acid salt is a soluble solid, which is convenient to be combined with effervescent tablets [17]. The effervescence reaction promotes the dispersion and dissolution of SHS, while the excess acid makes the extractant convert from soluble to insoluble to complete the extraction.

There are many different methods for phase separation. Centrifugation is a common method, but the centrifugation step is not convenient to operate on site [21]. However, there are still several ways to achieve onsite processing. Magnetic nanoparticles (MNPs) are a commonly used method. The extractant can be adsorbed on the MNPs. The magnets are then used to attract magnetic nanoparticles to achieve phase separation [16]. In addition, Xueke Liu et al. used 1-undecanol as an extractant and used a pipette to absorb the upper layer liquid to achieve on-site processing [22]. Recently, phase separation through filtration can also be performed well in the field [23]. Songqing Li et al. has completed the filtration step using non-woven polypropylene (NWPP), which has good lipophilic and hydrophobic properties [24]. However, there is no research to achieve the on-site pretreatment through the combination of effervescent tablet-assisted dispersion method and filtration by far.

Therefore, based on on-site processing, a method called effervescent tablet-assisted switchable hydrophilicity solvent-based on-site dispersion liquidliquid microextraction with filtration of homemade filter column (ETA-SHS-DLLME-FHC) was developed to determine pyrethroid pesticides in water. The method combined effervescent tablet-assisted dispersion with filtration for phase separation, and successfully completed microextraction and gas chromatography. The whole microextraction process does not rely on any special instruments, which makes this method successfully applied in the field. The effects of certain experimental parameters were also studied and optimized, such as the type and volume of the switchable solvent, the composition of the effervescent tablet, the amount of salt added, and the density and height of the filter device. The method was successfully applied to the detection of environmental waters in Beijing.

\section{Materials and methods}

\subsection{Reagents and materials}

Pyrethroid pesticides including bifenthrin, cyfluthrin, cypermethrin, fenvalerate, deltamethrin, were purchased from Tanmo Quality Inspection Technology Co., Ltd. (Jiangsu, China). Sodium hexanoate (99\%), sodium nonanoate (98\%) were purchased from J \& K Scientific (Beijing, China). Citric acid, sodium dihydrogen phosphate $\left(\mathrm{NaH}_{2} \mathrm{PO}_{4}\right)$, sodium bicarbonate $\left(\mathrm{NaHCO}_{3}\right)$, sodium carbonate $\left(\mathrm{Na}_{2} \mathrm{CO}_{3}\right)$ were all purchased from Macklin (Shanghai, China). Manual hydraulic tablet machine was purchased from Hebi Lixin Instrument Co., Ltd. (Henan, China). SPE column were purchased from Agilent Technologies (USA). Oil-absorbing cotton polypropylene (OCPP) and non-woven polypropylene (NWPP) were purchase from Suzhou Yilufa Environmental Protection Technology Co., Ltd. (Jiangsu, China).

\subsection{Instruments and equipments}

The gas chromatograph (GC Agilent 7890B, Agilent Technologies, Inc., USA) was equipped with an ECD detector. Analytes were separated in an DB-5 MS capillary column $(30 \mathrm{~m} \times 0.32 \mathrm{~mm} \times 0.25 \mu \mathrm{m})$. The injection volume was $1 \mu \mathrm{L}$ in all cases.

\subsection{Standard stock solutions and real samples}

Stock solutions of 5 pyrethroid standards $(2000 \mu \mathrm{g} / \mathrm{mL})$ were prepared in HPLC-grade acetonitrile. 5 kinds of standard solutions were mixed in equal volumes to prepare a mixed standard solution. The working standard solutions were obtained by diluting mixed standard solutions into different concentrations and stored in a refrigerator.

River water, reservoir water and tap water were collected by glass bottles from Beijing, China. They were protected from light and stored in a refrigerator.

\subsection{Preparation of effervescent tablets}

Firstly, $0.4992 \mathrm{~g}$ of citric acid, $0.4056 \mathrm{~g}$ of $\mathrm{NaH}_{2} \mathrm{PO}_{4}$, $0.2184 \mathrm{~g}$ of $\mathrm{NaHCO}_{3}$ and $0.18 \mathrm{~g}$ of sodium hexanoate were weighed by balance instrument. Then, the mixture was transferred into a mortar and manually ground until a uniform and fine powder was obtained. Next, the mixture was compressed by manual hydraulic tablet machine at pressure of $1 \mathrm{MPa}$. Finally, the resulting tablets $(12 \mathrm{~mm}$ id) were obtained which can be directly used for extraction or stored in an inert atmosphere.

\subsection{Preparation of homemade filter column}

As shown in Figure 1, the homemade filter column, as an important device for filtration, consists of three parts: SPE shell, OCPP and adapter device. Firstly, a $1 \mathrm{~mL}$ SPE column was intercepted to an appropriate height. Then, a gasket is placed at the bottom of the SPE. OCPP was cut into long strips of a certain height, rolled into a cylindrical shape and pack it into the SPE column. Another gasket was added on the top of the SPE. Finally, the homemade filter column was obtained by inserting the adapter above the column. 


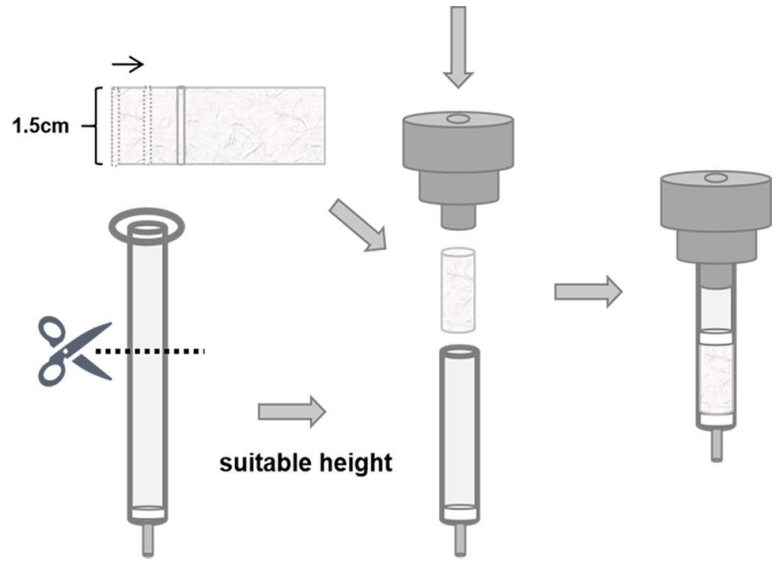

Fig. 1. Preparation of homemade filter column

\subsection{Extraction procedure}

Firstly, $10 \mathrm{~mL}$ of water sample were injected into a $20 \mathrm{~mL}$ syringe. Then, an effervescent tablet was added to the solution, and a full effervescent reaction and acid-base reaction have occurred. On the one hand, the extractant was fully dispersed by the effervescent reaction, on the other hand, the insoluble extractant formed during the acid-base reaction. When no bubbles generated, the system became emulsified and the extraction completed. Then, the solution in the syringe was filtrated by homemade filter column for phase separation. After filtration, the homemade filter column was blown to dry with a clean syringe. The analytes were eluted by $200 \mu \mathrm{L}$ of acetonitrile (ACN) and $1 \mu \mathrm{L}$ was injected for GC-ECD analysis.

\section{Results and discussion}

\subsection{Optimization of ETA-SHS-DLLME-FHC}

\subsubsection{Type of extractant}

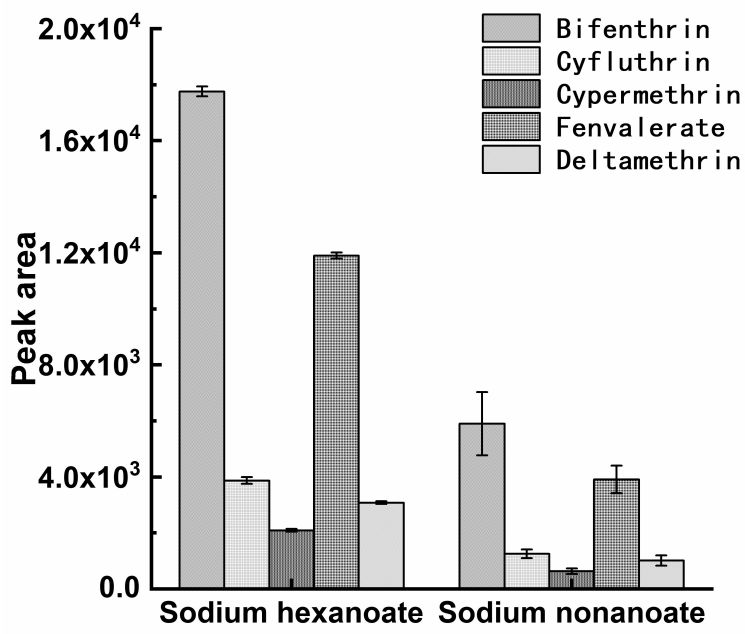

Fig. 2. Type of extractant. Microextraction conditions: effervescent tablet consists of $0.4992 \mathrm{~g}$ citric acid, $0.4056 \mathrm{~g}$ $\mathrm{NaH}_{2} \mathrm{PO}_{4}, 0.2184 \mathrm{~g} \mathrm{NaHCO}_{3}$; no salt; homemade filter column: OCPP filter with $2 \mathrm{~cm}$ height and $60 \mathrm{mg} \mathrm{cm}^{-1}$ density; $200 \mu \mathrm{L}$ ACN.
The extractant should have some advantageous characteristics, such as eco-friendly and low toxicity. The switchable fatty acid salts, sodium hexanoate and sodium nonanoate, were selected as extractants. Other invariable factors were as follows: the amount of fatty acid salt was $0.18 \mathrm{~g}$, the composition of an effervescent tablet was $0.4992 \mathrm{~g}$ of citric acid, $0.4056 \mathrm{~g}$ of $\mathrm{NaH}_{2} \mathrm{PO}_{4}$ and $0.2184 \mathrm{~g}$ of $\mathrm{NaHCO}_{3}$, the homemade filter column was filled with OCPP, and have $2 \mathrm{~cm}$ of height and $60 \mathrm{mg}$ $\mathrm{cm}^{-1}$ of density, the volume of eluent ACN was $200 \mu \mathrm{L}$. The results showed in Figure 2 indicated that sodium hexanoate has better extraction effect. Therefore, sodium hexanoate was used for subsequent experiments.

\subsubsection{Amount of extractant}

The amount of sodium hexanoate should be evaluated to obtain a suitable volume of extraction. In the experiment, different amounts of sodium hexanoate $(0.18,0.20$, $0.22 \mathrm{~g}$ ) were measured. As shown in Figure 3, the largest peak area was obtained at $0.18 \mathrm{~g}$. But the stability of the obtained results deteriorates when the extractant is less than $0.18 \mathrm{~g}$. Thus, considering the above factors, $0.18 \mathrm{~g}$ of sodium hexanoate was finally selected for subsequent experiments.

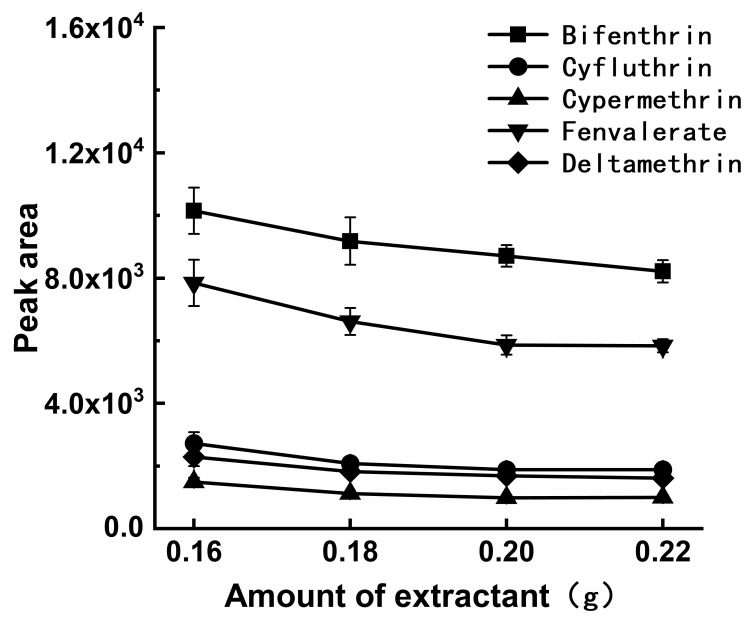

Fig. 3. Amount of extractant. Except for optimization conditions, other conditions are the same as above.

\subsubsection{Type of effervescent tablet}

The effervescent reaction has an important effect on the dispersion and extraction of the extractant. Different types of effervescent tablets produce different results in terms of reaction intensity and time. Therefore, four substances (citric acid, $\mathrm{NaH}_{2} \mathrm{PO}_{4}, \mathrm{NaHCO}_{3}$, and $\mathrm{Na}_{2} \mathrm{CO}_{3}$ ) were selected for determination. As shown in the Table 1, the four schemes were designed to gain a more performance in the experiment. Because the acid not only reacts with the base to produce $\mathrm{CO}_{2}$, but also reacts with the extractant, the strong acid of citric acid was chosen. At the same time, because the strong acid reacts quickly and easily to cause the problem of insufficient dispersion, $\mathrm{NaH}_{2} \mathrm{PO}_{4}$ was added as a regulator to make the reaction more complete. According to Figure 4, the effect of scheme A was the best, which have the best dispersion time and intensity. Therefore, scheme A 
(Citric acid $+\mathrm{Na}_{2} \mathrm{CO}_{3}+$ sodium hexanoate) was selected for subsequent determination.

Table 1. Scheme of effervescent tablets.

\begin{tabular}{|l|l|l|}
\hline Number & Scheme & Reaction time \\
\hline A & $\begin{array}{l}\text { Citric acid }+\mathrm{NaH}_{2} \mathrm{PO}_{4}+ \\
\text { NaHCO }\end{array}$ & $60 \mathrm{~s}$ \\
\hline $\mathrm{B}$ & $\begin{array}{l}\text { Citric acid }+\mathrm{NaH}_{2} \mathrm{PO}_{4}+ \\
\mathrm{Na}_{2} \mathrm{CO}_{3}+\text { sodium hexanoate }\end{array}$ & $80 \mathrm{~s}$ \\
\hline $\mathrm{C}$ & $\begin{array}{l}\text { Citric acid }+\mathrm{NaHCO}_{3}+ \\
\text { sodium hexanoate }\end{array}$ & $15 \mathrm{~s}$ \\
\hline $\mathrm{D}$ & $\begin{array}{l}\text { Citric acid }+\mathrm{Na}_{2} \mathrm{CO}_{3}+\text { sodium } \\
\text { hexanoate }\end{array}$ & $30 \mathrm{~s}$ \\
\hline
\end{tabular}

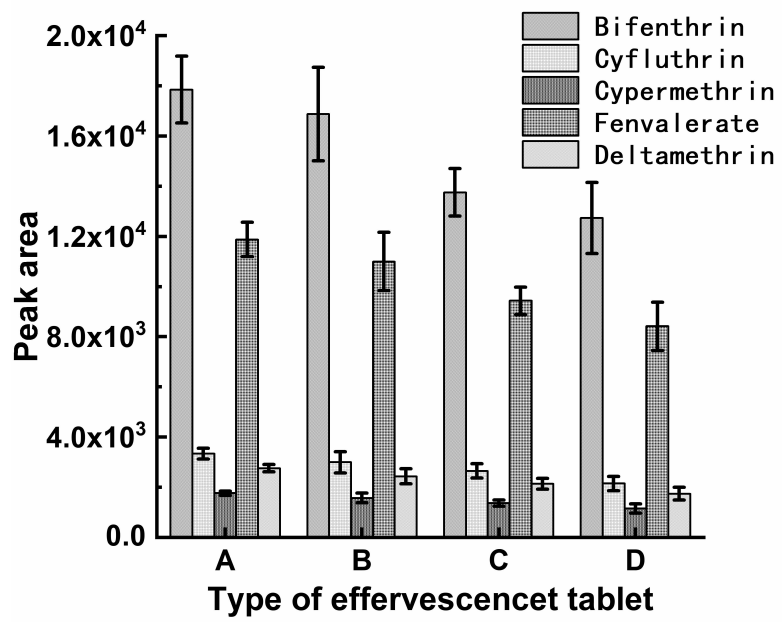

Fig. 4. Type of different effervescent tablets. Except for optimization conditions, other conditions are the same as above.

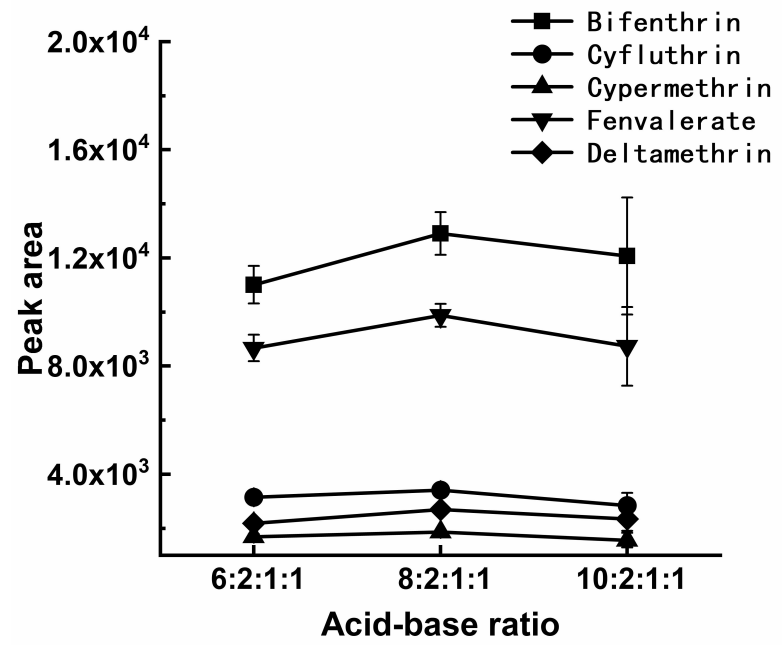

Fig. 5. Effect of acid-base ratio. Except for optimization conditions, other conditions are the same as above.

\subsubsection{Acid-base ratio}

Since the extraction agent of sodium hexanoate is easily affected by $\mathrm{pH}$, it is necessary to optimize the acid-base ratio of effervescent tablets. According to acid-base ionization theory, citric acid can produce three hydrogen ions, $\mathrm{NaH}_{2} \mathrm{PO}_{4}$ can produce one hydrogen ion, $\mathrm{NaHCO}_{3}$ and sodium hexanoate can produce one hydroxide ion. Therefore, optimization was performed according to different acid-base ratios (6:2:1:1, 8:2:1:1,10:2:1: 1). The results shown in Figure 5 was that the best peak area can be obtained during the citric acid: $\mathrm{NaH}_{2} \mathrm{PO}_{4}$ : $\mathrm{NaHCO}_{3}$ : sodium hexanoate ratio is $8: 2: 1: 1$. Therefore, $0.4992 \mathrm{~g}$ of citric acid, $0.4056 \mathrm{~g}$ of $\mathrm{NaH}_{2} \mathrm{PO}_{4}, 0.2184 \mathrm{~g}$ of $\mathrm{NaHCO}_{3}$, and $0.18 \mathrm{~g}$ of sodium hexanoate were weighed for experiments.

\subsubsection{Influence of salt addition}

The influence of salt concentration was examined by adding different quantities of salt into the water sample $(0-10 \%, w / v)$. Learning from Figure 6, with the increase of salt concentration, the response range of different pesticides showed differences. The $\mathrm{P}$ value of bifenthrin and cypermethrin was less than 0.01 , indicating that the difference was extremely significant, and it was greatly affected by the salt effect and had obvious inhibitory effect. However, the $\mathrm{P}$ value of cyfluthrin, fenvalerate, and deltamethrin were $>0.05$, the difference was not significant, and the change was not significant. In general, the increase in salt concentration has an inhibitory effect. Hence, no salt addition was chosen in the next experiments.

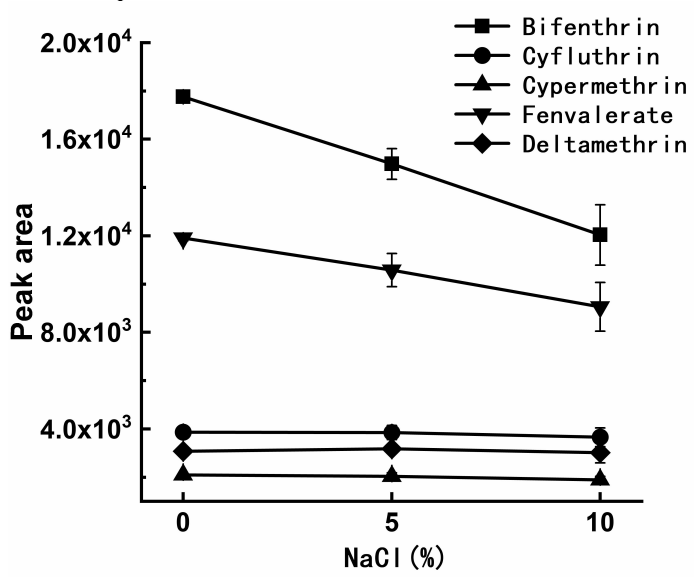

Fig. 6. Effect of salt addition. Except for optimization conditions, other conditions are the same as above.

\subsubsection{Type of filler of homemade filter column}

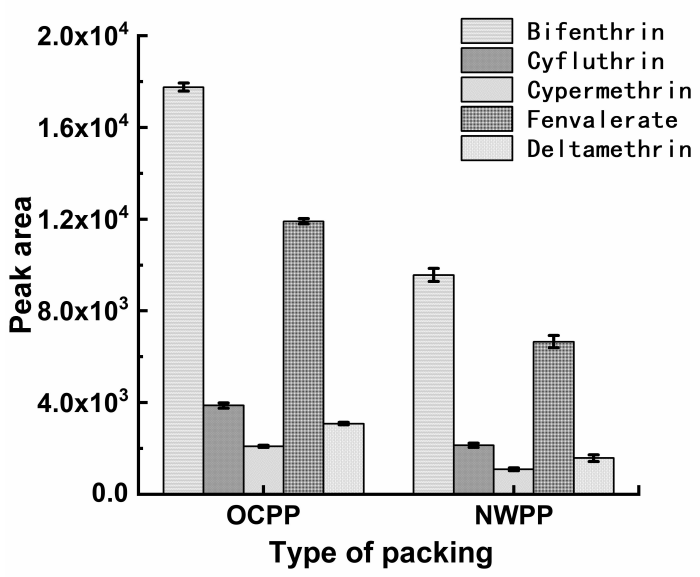

Fig. 7. Type of filter materials of homemade filter column. Except for optimization conditions, other conditions are the same as above.

Homemade filter column was an important device for phase separation. The filler materials of homemade filter 
column was an important factor affecting the separation effect. So it was necessary to be optimized. OCPP and NWPP were selected as filler materials for homemade filter columns. OCPP and NWPP have good lipophilic and hydrophobic properties, which can effectively adsorb the extractant but cannot adsorb water. Therefore, the filter column made with it can achieve a good filtering effect. Although they are all polypropylene materials, but still have different lipophilic and hydrophobic properties. The results showed in Figure 7 indicated that phase separation effect of the homemade filter column with OCPP filter is better than that of NWPP. Consequently, OCPP was used in subsequent experiments.

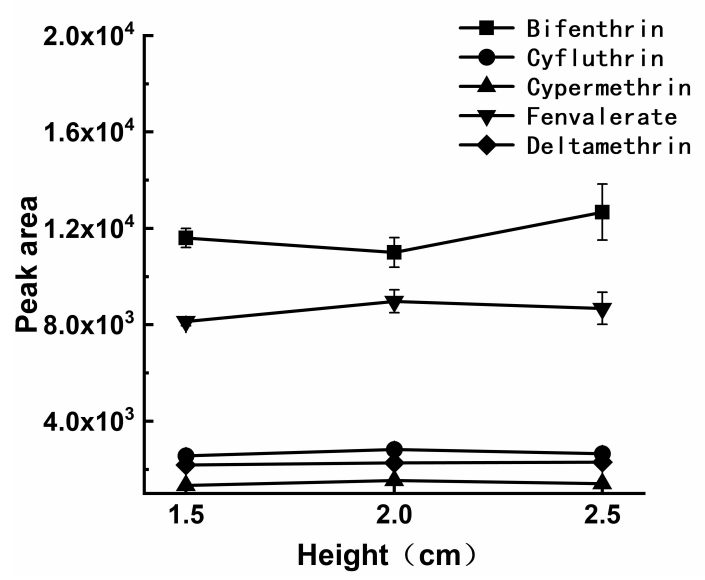

Fig. 8. Effect of height of homemade filter column filter. Except for optimization conditions, other conditions are the same as above.

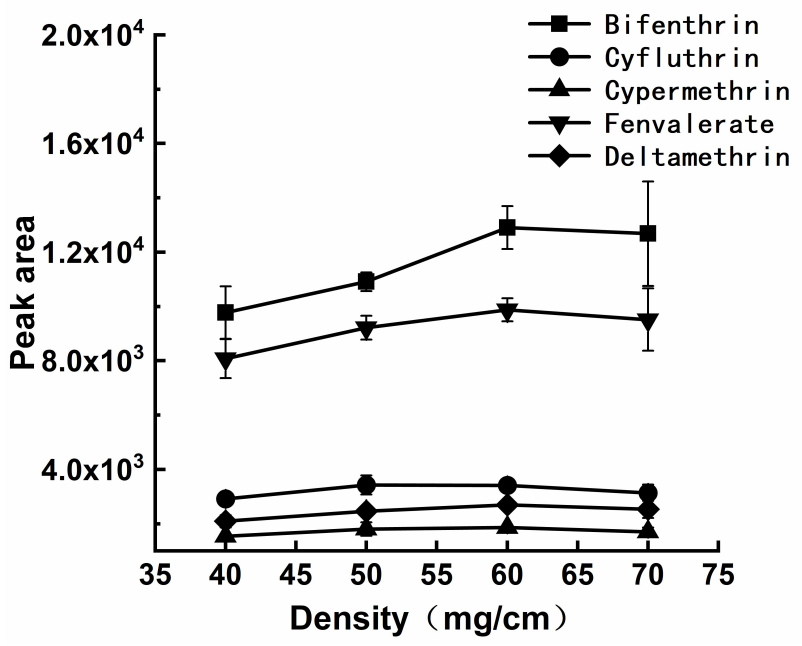

Fig. 9. Effect of density of homemade filter column filter. Except for optimization conditions, other conditions are the same as above.

\subsubsection{Height and density of homemade filter column}

The height and density of the homemade filter column have an impact on filtration performance. If the filter material is too tight, the filtering speed will be affected, and if the filter material is too sparse, the extractant will easily wash down. Therefore, it is necessary to be optimized. After optimization, the filter column can be flexibly changed as the amount of filtration changes, which is a good advantage. Thus, heights of filter column including $1.5,2.0$, and $2.5 \mathrm{~cm}$, were studied. As can be seen in Figure 8, the results indicated that the best peak area was obtained at $2.0 \mathrm{~cm}$. Thus, $2.0 \mathrm{~cm}$ of homemade filter column was selected for further studies.

Table 2. Analytical performances of the present method.

\begin{tabular}{|c|c|c|c|c|c|c|c|c|}
\hline \begin{tabular}{|l|} 
Pyrethroid \\
insecticides
\end{tabular} & $\begin{array}{l}\text { Linearity } \\
\left(\mu \mathrm{g} \mathrm{L}^{-1}\right)\end{array}$ & Linearity equation & $\mathrm{R}^{2}$ & $\begin{array}{l}\text { LOD } \\
\left(\mu \mathrm{g} \mathrm{L}^{-1}\right)\end{array}$ & $\begin{array}{l}\text { LOQ } \\
\left(\mu \mathrm{L} \mathrm{L}^{-1}\right)\end{array}$ & $\begin{array}{l}\text { RSD (\%) } \\
\text { intra-day }\end{array}$ & $\begin{array}{l}\text { RSD (\%) } \\
\text { inter-day }\end{array}$ & EF \\
\hline Bifenthrin & $5-500$ & $y=94.8 x-217.5$ & 0.9990 & 0.22 & 0.75 & 6.1 & 0.8 & 108 \\
\hline Cyfluthrin & $5-500$ & $y=24.916 x+67.895$ & 0.9994 & 1.03 & 3.45 & 2.2 & 5.4 & 71 \\
\hline Cypermethrin & $5-500$ & $y=13.341 x+42.416$ & 0.9996 & 1.65 & 5.49 & 3.0 & 4.6 & 65 \\
\hline Fenvalerate & $5-500$ & $y=68.004 x+165.82$ & 0.9996 & 0.39 & 1.29 & 4.3 & 2.9 & 66 \\
\hline Deltamethrin & $5-500$ & $y=21.184 x-51.306$ & 0.9999 & 1.88 & 6.25 & 1.9 & 1.3 & 93 \\
\hline
\end{tabular}

Table 3. Analytical performance of the proposed method for real samples.

\begin{tabular}{|l|l|l|l|l|l|l|l|}
\hline & Analytes & Tap water & & Reservoir water & & River water & \\
\hline $\begin{array}{l}\text { Pyrethroid } \\
\text { insecticides }\end{array}$ & $\begin{array}{l}\text { Spiked level } \\
(\mu \mathrm{g} \mathrm{L})\end{array}$ & $\begin{array}{l}\text { Relative } \\
\text { recovery }\end{array}$ & RSD $(\%)$ & $\begin{array}{l}\text { Relative } \\
\text { recovery }\end{array}$ & RSD $(\%)$ & $\begin{array}{l}\text { Relative } \\
\text { recovery }\end{array}$ & RSD (\%) \\
\hline Bifenthrin & 50 & 92.3 & 8.3 & 94.5 & 4.5 & 105.1 & 6.8 \\
\hline & 200 & 113.0 & 5.7 & 97.8 & 8.1 & 107.6 & 10.0 \\
\hline Cyfluthrin & 50 & 106.2 & 6.1 & 104.8 & 7.3 & 104.6 & 7.9 \\
\hline & 200 & 109.7 & 7.4 & 103.2 & 8.3 & 99.5 & 7.5 \\
\hline Cypermethrin & 50 & 98.2 & 7.5 & 96.4 & 7.9 & 97.5 & 9.3 \\
\hline & 200 & 108.5 & 5.7 & 99.1 & 9.2 & 100.2 & 8.9 \\
\hline Fenvalerate & 50 & 96.8 & 6.9 & 96.5 & 6.1 & 104.4 & 6.4 \\
\hline & 200 & 110.8 & 5.0 & 93.7 & 8.6 & 102.7 & 8.2 \\
\hline Deltamethrin & 50 & 88.2 & 8.6 & 88.7 & 5.2 & 97.1 & 8.8 \\
\hline & 200 & 101.6 & 6.0 & 89.6 & 10.2 & 98.8 & 11.8 \\
\hline
\end{tabular}


Table 4. Comparison of proposed method with others approaches.

\begin{tabular}{|c|c|c|c|c|c|c|c|c|}
\hline Methods & Detection & Analytes & Samples & $\begin{array}{l}\mathrm{LR} \\
\left(\mu \mathrm{g} \mathrm{L}^{-1}\right)\end{array}$ & $\begin{array}{l}\text { LOD } \\
\left(\mu \mathrm{g} \mathrm{L}^{-1}\right)\end{array}$ & $\begin{array}{l}\text { Centrifu } \\
\text {-gation }\end{array}$ & $\begin{array}{l}\text { On- } \\
\text { site }\end{array}$ & Refs. \\
\hline $\begin{array}{l}\text { EA-SFAM- } \\
\text { SFO }^{\mathrm{a}}\end{array}$ & HPLC-UV & FQs, TCs & $\begin{array}{l}\text { Sea water, } \\
\text { sediment, } \\
\text { seafood }\end{array}$ & $\begin{array}{l}0.024- \\
500\end{array}$ & $\begin{array}{l}0.007- \\
0.022\end{array}$ & Yes & No & {$[25]$} \\
\hline EA-DLLME & HPLC-DAD & acaricides & Honey & $1-500$ & $\begin{array}{l}0.04- \\
0.18\end{array}$ & Yes & No & {$[26]$} \\
\hline $\begin{array}{l}\text { EA-DLLME- } \\
\text { CFO }^{c}\end{array}$ & $\begin{array}{l}\text { UHPLC- } \\
\text { MS/MS }\end{array}$ & Herbicides, fungicides & $\begin{array}{l}\text { Water, grape } \\
\text { juice }\end{array}$ & $0.05-10$ & $\begin{array}{l}0.0027- \\
0.0097\end{array}$ & Yes & No & {$[27]$} \\
\hline $\begin{array}{l}\text { ETA-SHS-ME- } \\
\text { SFO }^{\mathrm{d}}\end{array}$ & HPLC-FLD & $\begin{array}{l}\text { endocrine disrupting } \\
\text { chemicals }\end{array}$ & $\begin{array}{l}\text { Water, juice, } \\
\text { drink }\end{array}$ & $30-3000$ & $0.2-0.7$ & Yes & No & {$[28]$} \\
\hline $\begin{array}{l}\text { MTEA-IL- } \\
\text { DLLME }^{\mathrm{e}}\end{array}$ & HPLC-DAD & fungicides & Water & $0.5-500$ & $\begin{array}{l}0.02- \\
0.10\end{array}$ & No & No & [29] \\
\hline $\begin{array}{l}\text { ETA-SHS- } \\
\text { DLLME-FHC }\end{array}$ & GC -ECD & pyrethroids & $\begin{array}{l}\text { Tap, } \\
\text { reservoir, } \\
\text { river water }\end{array}$ & $5-500$ & $\begin{array}{l}0.22- \\
1.88\end{array}$ & No & Yes & $\begin{array}{l}\text { This } \\
\text { work }\end{array}$ \\
\hline
\end{tabular}

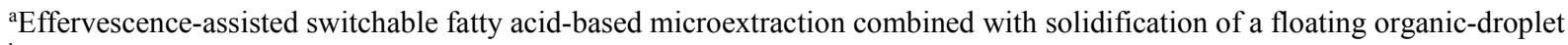

${ }^{b}$ Effervescence-assisted dispersive liquid-liquid microextraction

${ }^{c}$ Effervescence assisted dispersive liquid-liquid microextraction based on cohesive floating organic droplet

${ }^{\mathrm{d}}$ Magnetic effervescent tablet-assisted ionic liquid dispersive liquid-liquid microextraction

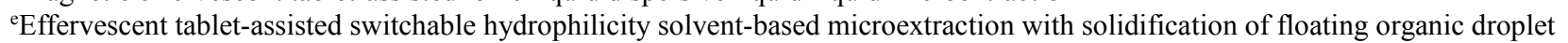

Using the height of $2.0 \mathrm{~cm}$, different filter densities $\left(40,50,60,70 \mathrm{mg} \mathrm{cm}^{-1}\right)$ were studied, and the results are shown in Figure 9. The peak area increased as the filter density from 40 to $60 \mathrm{mg} \mathrm{cm}^{-1}$ and then decreased from 60 to $70 \mathrm{mg} \mathrm{cm}^{-1}$. Therefore, the optimal density was $60 \mathrm{mg} \mathrm{cm}^{-1}$ and was used in the subsequent experiments.

\subsection{Method validation}

To evaluate the performance of the established method, the parameters including linearity, coefficient of determination $\left(\mathrm{R}^{2}\right)$, limits of detection (LOD), limits of quantification (LOQ), enrichment factor (EF), etc. were rigorously studied. As summarized in Table 2, good linearity $\left(\mathrm{R}^{2} \geq 0.9990\right)$ was achieved over the concentration range of $5-500 \mu \mathrm{g} \mathrm{L}^{-1}$. The LOD is calculated according to three times signal-to-noise ratio, and the LOQ is calculated according to ten times signalto-noise ratio. The LOD and the LOQ were in the range of $0.22-1.88 \mu \mathrm{g} \mathrm{L}^{-1}$ and $0.75-6.25 \mu \mathrm{g} \mathrm{L}^{-1}$. The results of the intra-day RSD were $1.9-6.1 \%$ and inter-day RSD were $0.8-5.4 \%$. The EF were obtained in the ranges of 65-108.

\subsection{Analysis of real samples}

To further validate the reliability and applicability of the developed method, the types of real samples need to be analysed. We collected three water samples including tap water, reservoir water and river water. The samples at different spiked concentration of 0,50 , and $200 \mu \mathrm{g} \mathrm{L}^{-1}$ were evaluated by the proposed method. The results were summarized in Table 3. The results of blank water samples were all negative and relative recoveries of the spiked samples were in the range of $88.2-113.0 \%$ with acceptable precision ranges $(4.5-11.8 \%)$. Hence, this method accurately detected environmental water samples.

\subsection{Comparison of ETA-SHS-DLLME-FHC with other methods}

As shown in Table 4, the established method was compared with other analytical methods. It can be seen from the comparison that most micro-extraction steps often require centrifugation to achieve phase separation which is one of the important and commonly used step. Therefore, these methods are difficult to perform on-site pretreatment operations [25-28]. In the meanwhile, some methods, such as solidification of floating organic droplets, do not require centrifugation, but centrifugation is required in the previous process [29]. Therefore, this method successfully realized that the entire sample pretreatment process does not require the use of electrical equipment, thereby realizing the on-site sample processing process. The on-site pretreatment of samples can greatly reduce the inconvenience caused by the transportation of a large number of samples and can reduce the manpower and material resources. Therefore, ETA-SHS-DLLME-FHC proved to be a convenient, green and low-toxic methods for the preconcentration of pyrethroid insecticides in water samples.

\section{Conclusion}

In this study, a convenient, green, economical, low-toxic method combined with gas chromatography was developed to determine five pyrethroid insecticides in environmental water. Effervescent assisted dispersion is a convenient, green and economical method that can effectively disperse the extractant. Homemade filter column, economical and easy to make, can effectively absorb the extractant and evacuate water. Therefore, the present method does not require additional instrument for phase dispersion and separation and has the potential to be applied to on-site processing which will greatly reduce transportation costs and reduce manpower and 
material resources. This method has successfully detected environmental water samples and has a broad space for development.

\section{Acknowledgment}

This work was supported by the National Natural Science Foundation of China under Grant [21707008].

\section{References}

[1] E. Ma, Z. Feng, Y. Zheng, Ekoloji 108 (2019)

[2] E. Matyjaszczyk, E. Karmilowicz, T. Skrzecz, For. Ecol. Manage. 433, 146 (2019)

[3] D. Jeong, J.S. Kang, K.M. Kim, S.H. Baek, S. Choe, J. Pyo, Forensic Sci.Int. 302 (2019)

[4] J. Lidova, M. Buric, A. Kouba, J. Velisek, Vet. Med. 64, 125 (2019)

[5] W. Deng, L. Yu, X. Li, J. Chen, X. Wang, Z. Deng, Y. Xiao, Food Chem. 274, 891 (2019)

[6] S. Chen, S. Gu, Y. Wang, Y. Yao, G. Wang, Y. Jin, Y. Wu, Environ. Pollut. 218, 1128 (2016)

[7] L. Sicupira, J. Tiago, G. de Pinho, F. Silvério, J. Braz. Chem. Soc. (2019)

[8] R. Ebrahimi Majdar, A. Ghasemian, H. Resalati, A. Saraeian, C. Crestini, H. Lange, Polymers 11, 225 (2019)

[9] D. Fracassetti, I. Vigentini, A.F.F. Lo Faro, P. De Nisi, R. Foschino, A. Tirelli, M. Orioli, M. Iriti, Foods 8, 99 (2019)

[10]A. Jouyban, M.A. Farajzadeh, M.R. Afshar Mogaddam, J Chromatogr B Analyt Technol Biomed Life Sci 1124, 114 (2019)

[11] M. Rezaee, Y. Assadi, M.R. Milani Hosseini, E. Aghaee, F. Ahmadi, S. Berijani, J. Chromatogr. A 1116, 1 (2006)

[12] J. Xue, X. Zhu, X. Wu, T. Shi, D. Zhang, R. Hua, J.
Sep. Sci. 42, 2993 (2019)

[13] E. Psillakis, Trac-Trends Anal. Chem. (2018)

[14] A. Elik, N. Altunay, R. Gürkan, Food Anal. Meth. 12, 489 (2018)

[15] Z. Zhong, G. Li, Z. Luo, B. Zhu, Talanta 194, 46 (2019)

[16] G. Lasarte-Aragones, R. Lucena, S. Cardenas, M. Valcarcel, Anal. Chim. Acta 807, 61 (2014)

[17] A. Shishov, I. Sviridov, I. Timofeeva, N. Chibisova, L. Moskvin, A. Bulatov, J. Mol. Liq. 247, 246 (2017)

[18] M. Hassan, U. Alshana, J. Pharm. Biomed. Anal. 174, 509 (2019)

[19] C.Vakh, A. Pochivalov, V. Andruch, L. Moskvin, A. Bulatov, Anal. Chim. Acta 907, 54 (2016)

[20] A. Ghoochani Moghadam, M. Rajabi, M. Hemmati, A. Asghari, J. Mol. Liq. 242, 1176 (2017)

[21] H. Piao, Y. Jiang, Z. Qin, S. Tao, P. Ma, Y. Sun, X. Wang, Talanta 208 (2020)

[22] X. Liu, Z. Shen, P. Wang, C. Liu, Z. Zhou, D. Liu, J. Chromatogr. A 1371, 58 (2014)

[23] M. Talaee, B. Lorestani, M. Ramezani, M. Cheraghi, S. Jamehbozorgi, J. Sep. Sci. 42, 2418 (2019)

[24] S. Li, L. Hu, K. Chen, H. Gao, Anal. Chim. Acta 872, 46 (2015)

[25] M. Gao, J. Wang, X. Song, X. He, R. Dahlgren, Z. Zhang, S. Ru, X. Wang, Anal. Bioanal. Chem. 410, 2671 (2018)

[26] X. Wu, X. Li, M. Yang, H. Zeng, S. Zhang, R. Lu, H. Gao, D. Xu, J. Chromatogr. A 1497, 1 (2017)

[27] X. Liu, C. Liu, P. Wang, G. Yao, D. Liu, Z. Zhou, Food Chem. 245, 653 (2018)

[28] X. Jing, J. He, W. Zhao, X. Huang, X. Wang, Microchem J. 155 (2020)

[29] M. Yang, X. Wu, Y. Jia, X. Xi, X. Yang, R. Lu, S. Zhang, H. Gao, W. Zhou, Anal. Chim. Acta 906, 118 (2016) 